\title{
Adjunctive therapy in Parkinson's disease: the role of rasagiline
}

This article was published in the following Dove Press journal:

Neuropsychiatric Disease and Treatment

29 June 2012

Number of times this article has been viewed

\section{Kathryn D Gaines' \\ Vanessa K Hinson ${ }^{2}$ \\ 'Department of Neurology, Aurora Advanced Healthcare, Milwaukee, WI, ${ }^{2}$ Department of Neurosciences, Movement Disorders Program, \\ Medical University of South Carolina, Charleston, SC, USA}

\begin{abstract}
Parkinson's disease is the second most common neurodegenerative disorder, currently affecting 1.5 million people in the US. In this review, we describe the diagnostic and pathological features of Parkinson's disease, as well as its clinical course. We then review pharmacologic treatments for the disease, with a particular focus on therapies adjunctive to levodopa and specifically the role of rasagiline. We review the four pivotal rasagiline trials, and discuss rasagiline and its use as adjunctive therapy for Parkinson's disease. Finally, we discuss potential side effects, drug interactions, and other practical aspects concerning the use of rasagiline in Parkinson's disease.
\end{abstract}

Keywords: Parkinson's disease, treatment, rasagiline, clinical trials

\section{Introduction}

Parkinson's disease (PD) is the second most common neurodegenerative disorder, currently affecting 1.5 million people in the US. ${ }^{1}$ The clinical picture of PD was astutely described by an apothecary surgeon, James Parkinson, in an historic paper entitled "An essay on the shaking palsy", published in 1817, yet it was not until years later that the malady of "paralysis agitans", also known as the shaking palsy, was given the name "Parkinson's disease" by Dr Jean Martin Charcot., ${ }^{2,3}$ The pathologic hallmark of PD is loss of dopaminergic neurons within the substantia nigra, as well as intracellular accumulation of Lewy bodies. ${ }^{4}$

\section{Parkinson's disease Cardinal clinical features}

The four cardinal clinical features of PD are tremor, bradykinesia, rigidity, and postural instability. The UK Parkinson's Disease Society Brain Bank criteria are the most commonly used guidelines for the diagnosis of idiopathic PD. ${ }^{5}$ Required is the presence of bradykinesia along with at least one of the following: muscular rigidity, 4-6 Hz rest tremor, and postural instability not caused by primary visual, vestibular, cerebellar, or proprioceptive dysfunction, along with careful consideration of exclusion and supportive criteria (Table 1). ${ }^{6}$ As such, unilateral or asymmetric presentation is often the norm, and a progressive advancement of symptoms, along with a favorable response to levodopa therapy, is commonly required to make the clinical diagnosis. In addition to these typical motor symptoms, PD patients frequently experience a number of nonmotor symptoms throughout the course of the disease. ${ }^{7}$ Common nonmotor symptoms are cognitive problems, ranging from mild cognitive impairment with 
Table I UK Parkinson's Disease Society Brain Bank diagnostic criteria for Parkinson's disease ${ }^{6}$

Step I Diagnosis of parkinsonism

Bradykinesia and at least one of the following:

- Muscular rigidity

- 4-6 Hz resting tremor

- Postural instability not caused by primary visual, vestibular, cerebellar or proprioceptive dysfunction

Step 2 Exclusion of idiopathic Parkinson's disease as the cause of parkinsonism

- History of repeated strokes with stepwise progression of parkinsonian features

- History of repeated head injury

- History of definite encephalitis

- Neuroleptic treatment at onset of symptoms

- At least one affected relative

- Sustained remission

- Strictly unilateral features after 3 years

- Supranuclear gaze palsy

- Cerebellar signs

- Early severe autonomic involvement

- Early severe dementia with disturbances of memory, language, and praxis

- Babinski's sign

- Presence of a cerebral tumor or communicating hydrocephalus on computed tomography scan

- Negative response to large doses of levodopa (malabsorption excluded)

- MPTP exposure

Step 3 Supportive of diagnosis of Parkinson's disease (three or more required for diagnosis of definite Parkinson's disease)

- Unilateral onset

- Rest tremor present

- Progressive disorder

- Persistent asymmetry affecting the side of onset most

- Excellent (70\%-100\%) response to levodopa

- Severe levodopa-induced chorea

- Levodopa response for $\geq 5$ years

- Clinical course of $\geq 10$ years

Abbreviation: MPTP, I-methyl-4-phenyl-1,2,3,6-tetrahydropyridine.

attention and set-shifting deficits early on, to frank dementia in some patients in the later stages of the disorder, as well as depression and anxiety. ${ }^{7}$ In addition, many PD patients suffer from pain syndromes and gastrointestinal problems, such as constipation, dysphagia, sialorrhea, and delayed gastric emptying. ${ }^{7,8}$ Other autonomic symptoms, such as hypotension, urinary dysfunction, and sexual dysfunction, frequently accompany the typical motor symptoms of PD at some point as well. ${ }^{78}$ In fact, as a synucleinopathy with progressive burden of intraneuronal Lewy bodies, the progression of nonmotor symptoms of PD can be correlated pathologically with accrual of Lewy bodies. Accumulation of Lewy bodies at Braak stage 1 starts at the level of the lower medulla oblongata, so symptoms such as impaired olfaction because of involvement of the olfactory nucleus are experienced. ${ }^{9}$ According to Braak staging, the neuropathologic changes of PD progress in an ascending fashion to next involve areas such as the great raphe nucleus, locus ceruleus, and reticular formation in stage 2 , before the basal portions of the midbrain, forebrain, and substantia nigra pars compacta are affected in stage 3 when the PD motor symptoms become noticeable. Stages 4-6 involve spread to the amygdala, mesocortex, and neocortex, and correlate with clinical progression and specifically development of dementia. ${ }^{9}$

\section{Pathogenesis}

A summary of pathologic findings in PD entails consideration of the decline and loss of dopaminergic cells within the substantia nigra pars compacta and Lewy body accumulation. ${ }^{10-13}$ At a deeper cellular level, creation of free oxygen radicals by disrupted antioxidative mechanisms creates damage to important proteins, as well as lipids and DNA, and thus damage to dopaminergic cells which are especially susceptible to oxidative stressors. ${ }^{14,15}$

The in vivo PD model created utilizing the compound 1-methyl-4-phenyl-1,2,3,6-tetrahydropyridine (MPTP) establishes the basic mechanism of PD by inducing loss of dopaminergic cells in animal models and has also been theorized to induce acquired parkinsonism in some humans after recreational consumption of an illicit drug containing the premetabolite. The MPTP compound is known to inhibit mitochondrial complex I. ${ }^{16,17}$

Given that contributing pathogenic factors combine to create the cellular changes inducing PD, microglial activation and astrocytic reactions in the substantia nigra have been implicated in post mortem studies as possible associated links. ${ }^{18-20}$ With activation of microglia and the associated cytokine cascade, a neuroinflammatory response has been documented in the brains of PD patients as well as via in vivo imaging studies demonstrating nigrostriatal dopaminergic terminal loss. ${ }^{21-29}$

With the knowledge that Lewy bodies are found in patients with PD and established as part of the pathologic process contributing to the mechanism of $\mathrm{PD}$, it is felt that the alpha synuclein found in Lewy bodies promotes accumulation of other Lewy bodies. ${ }^{30}$ In fact, alpha synuclein in the physiologic state exists in an alpha-helical conformation; however, in the pathologic state, it refolds into a beta sheet conformation and then promotes other alpha-helical synuclein proteins to reconfigure as well. ${ }^{31}$

Calcium homeostasis within the striatal dopamine structures is a critical process for maintaining adequate 
dopamine levels. This is achieved through a balance of intracellular calcium via ion channels. ${ }^{32,33}$ In PD patients, who already have a decrease in dopaminergic striatal cells, glutamatergic input in an attempt to activate and compensate for the dopaminergic loss ironically leads to glutamate excitotoxicity. ${ }^{34}$ Glutamate causes activation of NMDA and AMPA receptors which, in turn, activate voltage-gated ion channels, leading to an influx of extracellular calcium. ${ }^{35,36}$ This leads to a cascade of processes, which further promotes energy expenditure and subsequent mitochondrial damage and apoptosis. ${ }^{37-39}$

The mechanism of apoptosis or programmed cell death is felt to be another contributor in the pathogenesis of PD. ${ }^{13,40}$ Inflammatory processes that promote microglia may activate cell surface receptors for tumor necrosis factor as part of the extrinsic apoptotic process leading to dopaminergic cell death. ${ }^{41}$ Also, other cell surface receptors linked to the extrinsic apoptotic process are felt to be overexpressed in PD patients. ${ }^{7,42}$ Additionally, enhanced mitochondrial cell permeability leads to intrinsic apoptotic cell death and, as mentioned previously, can promote a neurotoxic cascade in an effort to balance dopamine concentrations. ${ }^{13}$

\section{Monotherapy}

Patients with early PD are usually managed with a single drug in monotherapy to address the motor symptoms of PD. Therapeutic choices for early PD are levodopa, dopamine agonists, monoamine oxidase type $\mathrm{B}$ inhibitors, amantadine, and trihexylphenidyl. Levodopa is considered the most effective treatment for the motor symptoms of PD. ${ }^{7}$ Levodopa requires active transportation across the blood-brain barrier and is then converted into dopamine by dopaminergic neurons via aromatic-L-amino acid decarboxylase. ${ }^{13}$ Nondopaminergic and glial cells also convert levodopa and the product is packed into vesicular monoamine transporter 2 vesicles at synaptic terminals. ${ }^{43-45}$ A substudy to the ELLDOPA (Earlier versus Later Levodopa) study, addressing the concern that levodopa could hasten the course of the disease, has rejected this hypothesis. ${ }^{46}$ Levodopa therapy has been shown to increase life expectancy in PD, is available at a low cost, and is usually well tolerated, even in the elderly patient. ${ }^{7,47}$ The major downside of levodopa therapy is its short half-life and the resultant pulsatile stimulation of dopamine receptors, leading to the development of motor fluctuations after several years of treatment. ${ }^{48}$ Motor fluctuations consist of periods of excessive movements or dyskinesias (most commonly at peak dose of levodopa), and periods of "off time", with paucity of movement, or akinesia. In order to avoid or delay the development of motor fluctuations, neurologists will often start younger patients on longer-acting dopamine agonists or monoamine oxidase B inhibitors first, or use levodopa as an adjunct to a longer-acting agent. The caveat here is that dopamine agonists are often poorly tolerated by the elderly and by cognitively impaired patients, so levodopa monotherapy, despite its limitations, is preferred in this setting.

\section{Need for adjunctive therapy}

Adjunctive therapy is most commonly used when motor fluctuations develop in a patient treated with levodopa (Table 2). Some clinicians will also use adjunctive treatment to keep the levodopa dosage low, in order to delay the onset of motor fluctuations, but there are no evidenced-based guidelines to support this practice. A common strategy to extend the half-life of levodopa is the addition of a catecholO-methyltransferase inhibitor such as entacapone or tolcapone, which can help the "wearing off" effect in between levodopa doses. Entacapone and tolcapone work to inhibit catechol-Omethyltransferase which otherwise causes the breakdown and degradation of levodopa. Entacapone acts peripherally and tolcapone acts both centrally and peripherally. ${ }^{4}$ While both are effective adjuncts, entacapone is usually the preferred agent due to concerns about hepatotoxicity with tolcapone and the resulting requirements for liver enzyme monitoring.?

Dopamine agonists, such as pramipexole and ropinirole, are utilized in early PD as monotherapy and for advanced $\mathrm{PD}$ in combination with levodopa, monoamine oxidase B inhibitors, or other adjuncts. ${ }^{7}$ Dopamine agonists work directly on dopamine receptors and do not depend on surviving dopaminergic cells or dopamine metabolism, as does levodopa ${ }^{13}$ Dopamine agonists have been shown to delay the onset of dyskinesias when used in monotherapy and to treat "wearing off" effectively when added to levodopa.

Monoamine oxidase inhibition is utilized to prevent degradation of dopamine and thus extends the length of usefulness of levodopa therapy or endogenous dopamine. Monoamine oxidase is normally found within the outer membrane of mitochondria, and its presence in the central nervous system accounts for a portion of oxidative degradation of dopamine as well as subsequent oxidative stress and further degradation of striatal neurons. ${ }^{49}$ In fact, within the central nervous system, it is the monoamine oxidase $\mathrm{B}$ enzyme that is predominant. By blocking the monoamine oxidase B enzyme, drugs such as selegiline and rasagiline have found usefulness as treatments for early PD and as adjunctive therapy.

\section{Selegiline}

Utilizing the notion that, of the two types of monoamine oxidase contained within the human body, the brain contains 
Table 2 Adjuncts to levodopa therapy ${ }^{5,7}$

\begin{tabular}{|c|c|c|}
\hline Dopamine agonists & Advantages & Weaknesses \\
\hline Pramipexole & $\begin{array}{l}\text { May lower amount of levodopa needed. } \\
\text { May decrease "off" time. }\end{array}$ & $\begin{array}{l}\text { May potentiate or cause hypotension, peripheral } \\
\text { edema, freezing of gait, hallucinations, excess } \\
\text { sleepiness, impulse control disorders, nausea. }\end{array}$ \\
\hline Ropinirole & As above. & As above. \\
\hline Mirapex ER ${ }^{\circledR}$ & $\begin{array}{l}\text { As above. May also be more effective at decreasing } \\
\text { "off' time and may be an alternative to other dopamine } \\
\text { agonists if dyskinesias are prominent. Dosed once daily. }\end{array}$ & As above. \\
\hline Requip $X^{\circledR}{ }^{\circledR}$ & As above. & As above. \\
\hline Apomorphine & Injectable rescue medicine for acute "off" time. & $\begin{array}{l}\text { Requires monitored titration. Requires } \\
\text { pretreatment with anti-emetic. Can cause } \\
\text { severe nausea, vomiting, hypotension, dyskinesias. }\end{array}$ \\
\hline \multicolumn{3}{|c|}{ Monoamine oxidase B inhibitors } \\
\hline Rasagiline & $\begin{array}{l}\text { Decreases wearing off. Dosed once daily. } \\
\text { Possible neuroprotection. Useful in early disease. }\end{array}$ & $\begin{array}{l}\text { Possible hypertensive crisis if combined with } \\
\text { excess tyramine rich foods. Contraindicated } \\
\text { in combination with certain anti-depressants. }\end{array}$ \\
\hline Selegiline & Decreases wearing off. & As above. \\
\hline Zydis selegiline & As above. Oral disintegrating. & As above. \\
\hline \multicolumn{3}{|c|}{ Catechol-O methyltransferase inhibitors } \\
\hline Entacapone & Decreases wearing off. & $\begin{array}{l}\text { May increase dyskinesias, cause nausea, } \\
\text { abdominal cramps and diarrhea. }\end{array}$ \\
\hline Tolcapone & As above. More potent than entacapone. & $\begin{array}{l}\text { As above. Requires hepatic function monitoring } \\
\text { every } 6 \text { months. }\end{array}$ \\
\hline \multicolumn{3}{|l|}{ Anticholinergics } \\
\hline Trihexylphenidyl & Improves tremor. & $\begin{array}{l}\text { Memory loss, confusion, dry mouth, urinary } \\
\text { retention, hallucinations. }\end{array}$ \\
\hline \multicolumn{3}{|l|}{ Antiviral } \\
\hline Amantadine & $\begin{array}{l}\text { Improves tremor. May improve freezing. } \\
\text { Reduces dyskinesias. }\end{array}$ & $\begin{array}{l}\text { Peripheral edema, livedo reticularis, hallucinations, } \\
\text { confusion. }\end{array}$ \\
\hline
\end{tabular}

mostly the monoamine oxidase type B enzyme, selegiline became noteworthy for its selective and irreversible binding to monoamine oxidase type $\mathrm{B}$ and thereby showed promise in exerting "antiakinetic" properties in PD patients treated with levodopa.${ }^{50}$ Previously known as (-) deprenyl, selegiline has been identified as a methamphetamine derivative with a propargyl group attached to a nitrogen molecule. With the discovery that positioning of the N-propargyl group chemically in relation to the "parent" aromatic ring helps to confer irreversibility and enzyme inhibition activity, other compounds were identified and tested for monoamine oxidase B inhibition properties as well. ${ }^{51}$

Selegiline has been demonstrated to lack the "cheese effect" despite high amounts of exogenous tyramine given in animal and human models, although theoretical questions have been posed regarding whether the lack of a tyramine effect remains despite chronicity of exposure to selegiline. ${ }^{52,53}$ In combination with levodopa, selegiline has been proven to be effective for mild "on-off" motor symptoms as well as motor akinesias. However, in some subjects, the combination of levodopa and selegiline promotes dyskinesias. ${ }^{54}$ DATATOP (deprenyl and tocopherol antioxidative therapy of parkinsonism) was a large, double-blind, placebo-controlled study comparing treatment of early PD patients with selegiline, tocopherol, or a combination of selegiline and tocopherol versus placebo. ${ }^{55}$ Selegiline, but not tocopherol, was found to delay time until disability requiring levodopa significantly, but because of its known symptomatic benefits, a neuroprotective effect could not be claimed..$^{56,57}$

\section{Rasagiline}

Rasagiline is a novel second-generation monoamine oxidase $B$ inhibitor that is selective and irreversible. Although selegiline is metabolized to L-methamphetamine and L-amphetamine via first-pass effects, rasagiline does not metabolize into an amphetamine derivative. ${ }^{58,59}$ The amphetamine metabolite of selegiline is felt to be neurotoxic, so any potential neuroprotective effect of selegiline is thus negated. ${ }^{60}$ On the other hand, rasagiline is an isomer of N-propargyl-1-aminoindan, which is a nonamphetamine metabolite. It is the propargyl chain that confers rasagiline with the irreversible and selective ability to inhibit monoamine oxidase $\mathrm{B}$ and is also thought to provide some degree of neuroprotection. ${ }^{51,61,62}$ Neurorescue effects have also been postulated based on the results of in vivo 
studies showing reduction of proapoptotic proteins and reduction of proteins signaling programmed cell death. ${ }^{63}$ Studies have also shown that treatment with propargylamine enhances expression of the cell survival genes GDNF and BDNF, which are both components felt to be important in neuroprotective and neurorescue activity toward dopaminergic and cholinergic neurons. ${ }^{63-65}$ Further proposed mechanisms by which rasagiline is felt to be neuroprotective include those in which there is upregulation of cellular antioxidant activity as well as the promotion of factors against apoptosis. ${ }^{66}$ The antioxidant activity is conferred as an increase in superoxide dismutase and catalase and the antiapoptotic potential is conferred due to stabilization of the mitochondrial membrane via binding of rasagiline to a portion of the membrane, which instigates the apoptotic process. ${ }^{67-70}$ Rasagiline also hinders the apoptotic process by downregulating proapoptotic proteins. ${ }^{71,72} \mathrm{~A}$ dose of $1 \mathrm{mg}$ in a PD patient reaches a maximal serum concentration within $0.5-0.7$ hours of ingestion. ${ }^{73,74}$ Although the terminal half-life is 1.34 hours, this does not correlate with biologic activity because restoration of monoamine oxidase $B$ activity depends on enzyme synthesis. Imaging studies measuring brain monoamine oxidase B occupancy after rasagiline dosing have indicated enzyme recovery may take up to 40 days in healthy populations. ${ }^{75}$ Studies in animal models have also supported the idea that rasagiline offers some amount of neuroprotection. For instance, pretreatment with rasagiline has attenuated the process by which MPTP utilizes the monoamine oxidase B enzyme and is transformed into a further potent neurotoxin in animal models. ${ }^{76,77}$

A possible disease-modifying effect has also been postulated after observing results of a human clinical trial using a novel delayed-start study design for rasagiline monotherapy in early PD, ie, the ADAGIO (Attenuation of Disease Progression with Azilect Given Once-daily) trial. ${ }^{78}$ The US Food and Drug Administration recently reviewed the ADAGIO trial and did not grant rasagiline an approved indication for neuroprotection. ${ }^{79}$ However, rasagiline is approved by the Food and Drug Administration as early monotherapy and also adjunctive therapy in $\mathrm{PD}$, based on the results of four pivotal clinical trials.

\section{Pivotal clinical trials}

The TEMPO (Rasagiline in Early Monotherapy for Parkinson's disease Outpatients) study utilized a delayedstart model, which was randomized and double-blinded. The purpose was to evaluate the safety and efficacy of rasagiline in PD patients who were not yet advanced enough in their disease to require levodopa therapy. ${ }^{80,81}$ The primary means of measuring drug efficacy was the change in total Unified Parkinson's Disease Rating Scale (UPDRS) score. The first half of the study period was 26 weeks long in total, included 404 patients with early $\mathrm{PD}$, and randomized patients to placebo or rasagiline $1 \mathrm{mg}$ or $2 \mathrm{mg}$ per day. After 6 months, the adjusted effect size (drug effect minus placebo effect) according to UPDRS score was -4.20 in the $1 \mathrm{mg}$ group and -3.56 in the $2 \mathrm{mg}$ group compared with placebo. After 6 months, the placebo group was switched to $2 \mathrm{mg}$ to become the delayed-start group. The groups assigned rasagiline $1 \mathrm{mg}$ and $2 \mathrm{mg}$ continued on for a further 6 months. A total of 371 patients completed this half of the study. Mean adjusted total UPDRS scores in the rasagiline $2 \mathrm{mg}$ group versus the delayed-start group showed a 2.29 unit smaller increase in score whereas the rasagiline $1 \mathrm{mg}$ group showed a 1.82 smaller increase in score versus the delayed-start group. Overall, the patients treated earlier than later had less functional decline, implying a potential neuroprotective effect since the delayed-start patients did not catch up to the early-start patients. ${ }^{82} \mathrm{~A}$ subsequent review of a subgroup of patients followed over a period of 4.5, 5.0, and 5.5 years demonstrated continued benefit and less progression compared with the delayed-start group and even continued a similar benefit beyond 6 years. ${ }^{83-85}$ The ADAGIO delayed-start trial was subsequently designed to help address the question of neuroprotection for PD patients.

In the ADAGIO trial, 1176 untreated PD subjects were enrolled and randomized to rasagiline at a dose of either $1 \mathrm{mg}$ or $2 \mathrm{mg}$ for 72 weeks or to placebo for the first 36 weeks and then rasagiline $1 \mathrm{mg}$ or $2 \mathrm{mg}$ for the remaining 36 weeks. Positive endpoint goals included: proving superiority to placebo in the rate of change in UPDRS scores between weeks 12 and 36; proving superiority compared with delayed-start treatment, as indicated by less change in UPDRS scores between baseline and week 72 ; and proving noninferiority to delayed-start treatment in the rate of change in UPDRS scores between weeks 48 and 72. In the early-start $1 \mathrm{mg}$ group, all three end points were achieved. The group that started $2 \mathrm{mg}$ early did not meet all three criteria based on the finding that there was no significant difference in change of UPDRS score between baseline and week 72 in the early-start versus delayed-start groups.

Two additional landmark trials specifically addressed the utility of adding rasagiline therapy onto the regimen for PD patients. The LARGO (Lasting Effect in Adjunct Therapy with Rasagiline Given Once Daily) study evaluated the safety and efficacy of adjunctive rasagiline therapy in patients treated with levodopa and compared this group with 
subjects taking either placebo and levodopa or entacapone and levodopa. Results of this 18 -week study revealed a similar reduction in "off" time for the rasagiline and entacapone adjunctive groups compared with placebo. Interestingly, a subanalysis found that the rasagiline group had significantly less freezing of gait, postural instability, and gait disturbance, as well as improved motor scores when the patient was "off" compared with those on placebo. ${ }^{86}$

In the PRESTO (Parkinson's Rasagiline: Efficacy and Safety in the Treatment of "Off") study, subjects with at least 2.5 hours of daily "off" time despite maximal levodopa treatment were randomized to receive rasagiline $0.5 \mathrm{mg} /$ day or $1 \mathrm{mg}$ /day or placebo along with their maximized levodopa regimen for a period of 26 weeks. If needed, the levodopa dose could be reduced within the first 6 weeks of the trial. Results of this study indicated that both the $0.5 \mathrm{mg}$ and $1 \mathrm{mg}$ rasagiline groups experienced reduction of "off" hours by 1.41 and 1.85 hours, respectively, compared with placebo, at 0.91 hours. Rasagiline was also found to improve clinical global impression scores significantly; UPDRS scores for activities of daily living during "off" time and UPDRS motor scores improved during "on" time in both the $0.5 \mathrm{mg}$ and $1 \mathrm{mg}$ groups when compared with placebo. In the rasagiline $0.5 \mathrm{mg}$ group that experienced increased "on" time and reduced "off" time, subjects experienced all of their increased "on" time without dyskinesias. The rasagiline $1 \mathrm{mg}$ group experienced some dyskinesias, with added improvement in "on" time. The total additional "on" time with dyskinesias was found to be a mean of 0.37 hours. Additionally, the rasagiline $0.5 \mathrm{mg}$ group experienced significant improvement in postural instability and gait and tremor during "on" times, and the rasagiline $1 \mathrm{mg}$ group experienced significant improvement in UPDRS subscores for rigidity, bradykinesia, and tremor. ${ }^{87}$

In all, the TEMPO, LARGO, PRESTO, and ADAGIO trials have demonstrated sustained improvement of motor function in patients with early PD, and also improvement in motor function and reduction of "off" hours, as well as improvement in difficult to treat postural instability, gait disturbance, and freezing of gait symptoms in patients with moderate to advanced PD and motor fluctuations.

\section{Side effects and interactions}

Rasagiline is generally well tolerated and, because of the lack of amphetamine metabolites, which in preclinical trials have shown adverse effects upon cardiovascular and psychiatric systems, has a more favorable side effect profile compared with selegiline, which often causes insomnia, confusion, and psychosis. ${ }^{88,89}$ Rates of dizziness, hypotension, confusion, and hallucinations were found to be no different from those on placebo in clinical trials of rasagiline..$^{80,81,86,87}$ Goetz et al performed a post hoc analysis of the TEMPO and PRESTO trials in order to evaluate the safety of rasagiline specifically in the elderly, given that this population is especially prone to side effects from drugs used in Parkinson's disease. ${ }^{90}$ Analysis of the data from these trials for patients aged 70 years or older did not show any statistically significant association between side effects, age, and use of rasagiline. Although adverse events occurred more frequently in the elderly, this was irrespective of treatment with rasagiline or placebo..$^{90}$ Table 3 summarizes the adverse events encountered in one or more of the four pivotal trials. The tyramine or "cheese" reaction whereby a heightened vasopressor response is experienced when dietary tyramine is combined with monoamine oxidase inhibitors, was not associated with administration of rasagiline, even when the amount of tyramine exceeded typical dietary intake. ${ }^{91,92}$ Serotonin syndrome, on the other hand, is a risk in patients taking either selegiline or rasagiline in combination with meperidine. ${ }^{93,94}$ Furthermore, concomitant use of tramadol, methadone, propoxyphene, dextromethorphan, cyclobenzaprine, and St John's wort are contraindicated in patients taking rasagiline, according to the prescribing information. ${ }^{95}$ Although there were a limited number of patients taking selective serotonin reuptake inhibitors in the TEMPO, LARGO, PRESTO, and ADAGIO trials, no patients were reported to suffer from serotonin syndrome while participating in these studies. ${ }^{67,80,81,86,87,94}$ Fluoxetine and fluvoxamine were not allowed to be used during the trials due to their long half-lives. ${ }^{94}$ However, in the postmarketing period, nonfatal cases of serotonin syndrome have been reported in patients treated concomitantly with antidepressants and rasagiline. ${ }^{95}$

Drug interactions involving the cytochrome P450 (CYP isoenzymes) and rasagiline are of concern. CYP inhibitors such as ciprofloxacin, cimetidine, and fluvoxamine can significantly increase the area under the concentration-time curve for rasagiline. ${ }^{94,96}$ Prescribing recommendations state that rasagiline dosing should not exceed $0.5 \mathrm{mg}$ daily in patients taking CYP inhibitors and that the dose should be reduced in patients with mild hepatic impairment. ${ }^{97}$ On the other hand, CYP inducers such as omeprazole can decrease the area under the curve for rasagiline. ${ }^{94}$ A summary of contraindications to rasagiline therapy is outlined in Table 4.

\section{Potential benefits on cognition and quality of life}

In addition to treating the motor symptoms of $\mathrm{PD}$, rasagiline has shown promise in the realm of enhancing cognition. 
Table 3 Adverse events from pivotal clinical trials

\begin{tabular}{|c|c|c|}
\hline & & Reference \\
\hline TEMPO & CV: $2 \%$ combined chest pain, aortic aneurysm, cardiac bypass, atrial fibrillation & 80 \\
\hline Placebo $=138$ & Gl: $6 \%$ nausea & \\
\hline I mg dose $=134$ & Neurological: $13.2 \%$ headache, $7 \%$ dizziness, $4.5 \%$ asthenia & \\
\hline \multirow[t]{2}{*}{$2 \mathrm{mg}$ dose $=132$} & MSK: $7.1 \%$ arthralgias, $5.6 \%$ back pain, $5.3 \%$ generalized pain & \\
\hline & Other: $15.4 \%$ infection, $7.5 \%$ accidental injury & \\
\hline PRESTO & GI: $5 \%$ weight loss, $5 \%$ vomiting, $3 \%$ anorexia & 87 \\
\hline Placebo = 159 & Neurological: $4 \%$ impaired balance & \\
\hline \multicolumn{3}{|l|}{$0.5 \mathrm{mg}$ dose $=164$} \\
\hline \multicolumn{3}{|l|}{ I mg dose = I49 } \\
\hline LARGO & CV: $2 \%$ postural hypotension, $1 \%$ syncope & 86 \\
\hline Placebo $=229$ & GI: I\% constipation, I\% diarrhea, $2 \%$ dry mouth, $3 \%$ nausea, I\% vomiting & \\
\hline \multirow[t]{3}{*}{ I $\mathrm{mg}$ dose $=23 \mathrm{I}$} & Metabolic: $2 \%$ peripheral edema & \\
\hline & Neurological: I\% abnormal dreams, $2 \%$ anxiety, 3\% depression, $5 \%$ dyskinesias, & \\
\hline & $2 \%$ hallucinations, $3 \%$ sleep disorders, $1 \%$ somnolence & \\
\hline ADAGIO & CV: $2 \%$ hypertension, $1.7 \%$ orthostatic hypotension & 78 \\
\hline Placebo $=595$ & $\mathrm{Gl}: 3 \%$ nausea and vomiting & \\
\hline I mg dose $=543$ & Neurological: $5 \%$ headache, $1 \%$ somnolence, $<1 \%$ hallucinations & \\
\hline \multirow[t]{2}{*}{$2 \mathrm{mg}$ dose $=548$} & MSK: 5\% back pain, 5\% arthralgias, 3\% musculoskeletal pain & \\
\hline & Other: $5 \%$ nasopharyngitis & \\
\hline
\end{tabular}

Abbreviations: CV, cardiovascular; GI, gastrointestinal; MSK, musculoskeletal; ADAGIO, Attenuation of Disease Progression with Azilect Given Once-daily; LARGO, Lasting Effect in Adjunct Therapy with Rasagiline Given Once Daily; PRESTO, Parkinson's Rasagiline: Efficacy and Safety in the Treatment of “Off”; TEMPO, Rasagiline in Early Monotherapy for Parkinson's disease Outpatients.

A multicenter, double-blind, placebo-controlled trial has recently been conducted involving 55 nondemented but cognitively impaired PD patients. ${ }^{98}$ The study was conducted over 12 weeks and patients on dopaminergic treatment were randomized to receive either placebo or rasagiline $1 \mathrm{mg}$.

Table 4 Contraindications and other considerations for rasagiline dosing

\begin{tabular}{|c|c|}
\hline & Reference \\
\hline $\begin{array}{l}\text { Rasagiline is contraindicated in the following scenarios } \\
\text { In patients taking any one of the following } \\
\text { - Meperidine } \\
\text { - Tramadol } \\
\text { - Methadone } \\
\text { - Propoxyphene } \\
\text { - Detromethorphan } \\
\text { - St John's wort } \\
\text { - Cyclobenzaprine } \\
\text { - Other MAOls }\end{array}$ & $93,94,95$ \\
\hline $\begin{array}{l}\text { Rasagiline dosing should be reduced to } 0.5 \mathrm{mg} / \text { day } \\
\text { and caution used in the following scenarios } \\
\text { In patients taking CYPIA2 inhibitors such as } \\
\text { - Ciprofloxacin } \\
\text { - Cimetidine } \\
\text { In patients with the following } \\
\text { - Mild hepatic impairment }\end{array}$ & 97 \\
\hline $\begin{array}{l}\text { Rasagiline should also be avoided in the following } \\
\text { scenarios } \\
\text { - Patients with moderate to severe hepatic impairment } \\
\text { - Patients taking fluoxetine or fluvoxamine }\end{array}$ & $94,95,96$ \\
\hline
\end{tabular}

Neuropsychologic assessment was performed at baseline and at the end of the 12-week period. A significant improvement was found in a test measure of attention as well as a suggestion of benefit in the area of executive function, with significant improvements seen in a test of verbal fluency. There was a trend toward improvement in semantic verbal fluency as well. However, the trial did not show improvement in memory or visual-spatial domains. ${ }^{98}$

A cost-utility study by Hudry et al, performed in Finland, compared levodopa therapy alone (standard care) versus rasagiline with levodopa and entacapone with levodopa, measuring quality-adjusted life-years and number of months spent with less than $25 \%$ of "off" time. Parity pricing for rasagiline and entacapone was assumed, based on the World Health Organization daily drug dose system. The study showed adjunctive rasagiline therapy to have greater cost-effectiveness and cost reductions compared with standard care, per treated patient. After 2 years, rasagiline showed 0.13 (95\% confidence interval $0.08-0.17)$ additional quality-adjusted life-years and 5.2 (3.6-6.7) additional months of reduced "off" time compared with levodopa alone..$^{99}$

\section{Practical applications}

When faced with the clinical problem of treating motor fluctuations in PD, adjunctive therapy with longer-acting agents in addition to short-acting levodopa is often needed. 
Rasagiline is an effective and well tolerated adjunctive medication in this setting, and is proven to reduce "off" time to an extent similar to that of entacapone. Adjunctive rasagiline is usually initiated at a dose of $0.5 \mathrm{mg}$ in the morning, and can be increased if needed to $1 \mathrm{mg}$ daily given in a single dose. Levodopa therapy or other concomitant PD drugs might have to be reduced after addition of rasagiline if dyskinesias occur. Rasagiline is an attractive choice in this setting because of the potential for neuroprotection based on preclinical and clinical data (even though the drug is not approved by the Food and Drug Administration for this indication), as well as easy once-daily dosing, favorable tolerability compared with selegiline (amphetamine metabolite) or dopamine agonists (often cause sedation, orthostasis, psychosis and dopamine dysregulation syndrome), and the suggestion from clinical trials of a potential effect on cognition, freezing of gait, and postural instability. The disadvantages of rasagiline therapy are related to cost (currently no generic formulation is available), and a number of potential drug-drug interactions that have to be carefully considered prior to the decision to initiate rasagiline therapy.

\section{Disclosure}

KDG has received speaking honoraria from Medtronic and Teva Pharmaceuticals. VKH has received consulting and speaking honoraria from Teva Pharmaceuticals.

\section{References}

1. Parkinson.org [homepage on the Internet]. Oberdorf J, Schmidt P. Improving care for people with Parkinson's disease. National Parkinson Foundation. Feb 2010. Available from: http://www.parkinson.org/ NationalParkinsonFoundation/files/c2/c2abb799-4e2b-41c5-8c06-47f3424a58d0.pdf. Accessed February 6, 2012.

2. Parkinson J. An essay on the shaking palsy. 1817. J Neuropsychiatry Clin Neurosci. 2002;14(2):223-236.

3. Haas LF. Jean Martin Charcot (1825-1893) and Jean Baptiste Charcot (1867-1936). J Neurol Neurosurg Psychiatry. 2001;71(4):524.

4. Siderowf A, Stern M. Update on Parkinson disease. Ann Intern Med. 2003;138(8):651-658.

5. Suchowersky O, Reich S, Perlmutter J, et al. Practice parameter: diagnosis and prognosis of new onset Parkinson disease (an evidence-based review): report of the Quality Standards Subcommittee of the American Academy of Neurology. Neurology. 2006;66(7):968-975.

6. Hughes AJ, Daniel SE, Kilford L, Lees AJ. Accuracy of clinical diagnosis of idiopathic Parkinson's disease: a clinicopathological study of 100 cases. J Neurol Neurosurg Psychiatry. 1992;55(3):181-184.

7. Zesiewicz T, Hauser R. Medical treatment of motor and nonmotor features of Parkinson's disease. Continuum. 2007;13(1):12-38.

8. Miyasaki JM, Shannon K, Voon V, et al. Practice parameter: Evaluation and treatment of depression, psychosis, and dementia in Parkinson disease (an evidence-based review). Report of the Quality Standards of Subcommittee of the American Academy of Neurology. Continuum. 2007;13(1):193-201.

9. Braak H, Bohl J, Muller C, et al. Stanley Fahn Lecture 2005: The staging procedure for the inclusion body pathology associated with sporadic Parkinson's disease reconsidered. Mov Disord. 2006;21(12):2042-2051.
10. Forno LS. Concentric hyaline intraneuronal inclusions of Lewy type in the brains of elderly persons (50 incidental cases): relationship to parkinsonism. J Am Geriatr Soc. 1969;17(6):557-575.

11. Ishiyama M, Yagishita S, Hasegawa K, Yokoyama T. Ultrastructural study (transmission and scanning EM) of cortical Lewy bodies. Neuropathology. 2006;26(2):A58.

12. Braak H, Del Tredici K, Rub U, de Vos RA, Jansen Steur EN, Braak E. Staging of brain pathology related to sporadic Parkinson's disease. Neurobiol Aging. 2003;24(2):197-211.

13. Kincses ZT, Vecsei L. Pharmacological therapy in Parkinson's disease: focus on neuroprotection. CNS Neurosci Ther. 2011;17(5):345-367.

14. Bogaerts V, Theuns J, van Broeckhoven C. Genetic findings in Parkinson's disease and translation into treatment: a leading role for mitochondria? Genes Brain Behav. 2008;7(2):129-151.

15. Maker HS, Weiss C, Silides DJ, Cohen G. Coupling of dopamine oxidation (monoamine oxidase activity) to glutathione oxidation via the generation of hydrogen peroxide in rat brain homogenates. J Neurochem. 1981;36(2):589-593.

16. Gerlach M, Riederer P, Przuntek H, Youdim MB. MPTP mechanisms of neurotoxicity and their implications for Parkinson's disease. Eur J Pharmacol. 1991;208(4):273-286.

17. Langston JW, Ballard P, Tetrud JW, Irwin I. Chronic parkinsonism in humans due to a product of meperidine-analog synthesis. Science. 1983;219(4587):979-980.

18. McGeer PL, Itagaki S, Boyes BE, McGeer EG. Reactive microglias are positive for HLA-DR in the substantia nigra of Parkinson's and Alzheimer's disease brains. Neurology. 1988;38(8):1285-1291.

19. Imamura K, Hishikawa N, Sawada M, Nagatsu T, Yoshida M, Hashizume Y. Distribution of major histocompatibility complex class II-positive microglia and cytokine profile of Parkinson's disease brains. Acta Neuropathol (Berl). 2003;106(6):518-526.

20. Mirza B, Hadberg H, Thomsen P, Moos T. The absence of reactive astrocytosis is indicative of a unique inflammatory process in Parkinson's disease. Neuroscience. 2000;95(2):425-432.

21. Mogi M, Harada M, Narabayashi H, Inagaki H, Minami M, Nagatsu T. Interleukin (IL)-1 beta, IL-2, IL-4, IL-6 and transforming growth factor-alpha levels are elevated in ventricular cerebrospinal fluid in juvenile parkinsonism and Parkinson's disease. Neurosci Lett. 1996; 211(1):13-16.

22. Mogi M, Harada M, Kondo T, Riederer P, Nagatsu T. Interleukin-2 but not basic fibroblast growth factor is elevated in parkinsonian brain. Short communication. J Neural Transm. 1996;103(8-9):1077-1081.

23. Mogi M, Harada M, Kondo T, Narabayashi H, Riederer P, Nagatsu T. Transforming growth factor-beta 1 levels are elevated in the striatum and in ventricular cerebrospinal fluid in Parkinson's disease. Neurosci Lett. 1995;193(2):129-132.

24. Mogi M, Harada M, Kondo T, Riederer P, Nagatsu T. Brain beta 2-microglobulin levels are elevated in the striatum in Parkinson's disease. J Neural Transm Park Dis Dement Sect. 1995;9(1): $87-92$.

25. Mogi M, Harada M, Kondo T, et al. Interleukin-1 beta, interleukin-6, epidermal growth factor and transforming growth factor-alpha are elevated in the brain from parkinsonian patients. Neurosci Lett. 1994;180(2):147-150.

26. Mogi M, Harada M, Riederer P, Narabayashi H, Fujita K, Nagatsu T. Tumor necrosis factor-alpha (TNF-alpha) increases both in the brain and in the cerebrospinal fluid from parkinsonian patients. Neurosci Lett. 1994;165(1-2):208-210.

27. Mogi M, Harada M, Kojima K, et al. Beta 2-microglobulin decrease in cerebrospinal fluid from parkinsonian patients. Neurosci Lett. 1989;104(1-2):241-246.

28. Gerhard A, Pavese N, Hotton G, et al. In vivo imaging of microglial activation with $[11 \mathrm{C}](\mathrm{R})-\mathrm{PK} 11195$ PET in idiopathic Parkinson's disease. Neurobiol Dis. 2006;21(2):404-412.

29. Ouchi Y, Yoshikawa E, Sekine Y, et al. Microglial activation and dopamine terminal loss in early Parkinson's disease. Ann Neurol. 2005; 57(2):168-175. 
30. Chau KY, Ching HL, Schapira AH, Cooper JM. Relationship between alpha synuclein phosphorylation, proteasomal inhibition and cell death: relevance to Parkinson's disease pathogenesis. J Neurochem. 2009;110(3):1005-1013.

31. Olanow CW, Prusiner SB. Is Parkinson's disease a prion disorder? Proc Natl Acad Sci U S A. 2009;106(31):12571-12572.

32. Bonci A, Grillner P, Mercuri NB, Bernardi G. L-Type calcium channels mediate a slow excitatory synaptic transmission in rat midbrain dopaminergic neurons. J Neurosci. 1998;18(17):6693-6703.

33. Ping HX, Shepard PD. Apamin-sensitive $\mathrm{Ca}(2+)$-activated $\mathrm{K}+$ channels regulate pacemaker activity in nigral dopamine neurons. Neuroreport. 1996;7(3):809-814.

34. Rodriguez MC, Obeso JA, Olanow CW. Subthalamic nucleus-mediated excitotoxicity in Parkinson's disease: a target for neuroprotection. Ann Neurol. 1998;44(3 Suppl 1):S175-S188.

35. Dingledine R, Borges K, Bowie D, Traynelis SF. The glutamate receptor ion channels. Pharmacol Rev. 1999;51(1):7-61.

36. Greenamyre JT, Porter RH. Anatomy and physiology of glutamate in the CNS. Neurology. 1994;44(11 Supp1 88):S7-S13.

37. Hetz CA. ER stress signaling and the BCL-2 family of proteins: from adaptation to irreversible cellular damage. Antioxid Redox Signal. 2007;9(12):2345-2355.

38. Lindholm D, Wootz H, Korhonen L. ER stress and neurodegenerative diseases. Cell Death Differ. 2006;13(3):385-392.

39. Gheorghiade M, Konstam MA, Burnett JC Jr, et al. Short-term clinical effects of tolvaptan, an oral vasopressin antagonist, in patients hospitalized for heart failure: the EVEREST Clinical Status Trials. JAMA 2007;297(12):1332-1343

40. Kerr JF, Wyllie AH, Currie AR. Apoptosis: a basic biological phenomenon with wide-ranging implications in tissue kinetics. $\mathrm{Br} J$ Cancer. 1972;26(4):239-257.

41. Hirsch EC, Hunot S. Neuroinflammation in Parkinson's disease: a target for neuroprotection? Lancet Neurol. 2009;8(4):382-397.

42. Ferrer I, Blanco R, Cutillas B, Ambrosio S. Fas and Fas-L expression in Huntington's disease and Parkinson's disease. Neuropathol Appl Neurobiol. 2000;26(5):424-433.

43. Huot P, Parent A. Dopaminergic neurons intrinsic to the striatum J Neurochem. 2007;101(6):1441-1447.

44. Kitahama K, Geffard M, Araneda S, et al. Localization of L-DOPA uptake and decarboxylating neuronal structures in the cat brain using dopamine immunohistochemistry. Brain Res. 2007;1167: 56-70.

45. Yamada H, Aimi Y, Nagatsu I, Taki K, Kudo M, Arai R. Immunohistochemical detection of L-DOPA-derived dopamine within serotonergic fibers in the striatum and the substantia nigra pars reticulata in Parkinsonian model rats. Neurosci Res. 2007;59(1):1-7.

46. Fahn S; and the Parkinson Study Group. Does levodopa slow or hasten the rate of progression of Parkinson's disease? J Neurol. 2005;252 Suppl 4 IV37-IV42.

47. Rajput AH, Uitti R, Rajput A, et al. Timely levodopa (LD) administration prolongs survival in Parkinson's disease. Parkinsonism Relat Disord. 1997;3(3):159-165.

48. Zesiewicz T, Sullivan K, Hauser R. Levodopa-induced dyskinesia in Parkinson's disease: epidemiology, etiology and treatment. Curr Neurol Neurosci Rep. 2007;7(4):302-310.

49. Dostert PL, Strolin Benedetti M, Tipton KF. Interactions of monoamine oxidase with substrates and inhibitors. Med Res Rev. 1989;9(1):45-89.

50. Birkmayer W, Riederer P, Youdim MBH, Linauer W. The potentiation of the anti akinetic effect after L-dopa treatment by an inhibitor of MAO-B, Deprenyl. J Neural Trans. 1975;36(3-4):303-326.

51. Kalir A, Sabbagh A, Youdim MBH. Selective acetylenic 'suicide' and reversible inhibitors of monoamine oxidase types A and B Br J Pharmacol. 1981;73(1):55-64.

52. Sandler M, Glover V, Ashford A, Stern GM. Absence of "cheese effect" during deprenyl therapy: some recent studies. J Neural Trans. 1978;43(3-4):209-215.
53. Elsworth JD, Glover V, Reynolds GP, et al. Deprenyl administration in man: a selective monoamine oxidase B inhibitor without the "cheese effect'. Psychopharmacology. 1978;57(1):33-38.

54. Lees AJ, Kohout LJ, Shaw KM, et al. Deprenyl in Parkinson's disease. Lancet. 1997;310 (8042):791-795.

55. Parkinson Study Group. DATATOP: a multicenter controlled clinical trial in early Parkinson's disease. Arch Neurol. 1989;46(10):1052-1060.

56. LeWitt PA. Neuroprotection by anti-oxidant strategies in Parkinson's disease. Eur Neurol. 1993;33 Suppl 1:24-30.

57. Shoulson I. DATATOP: a decade of neuroprotective inquiry. Parkinson Study Group. Deprenyl and tocopherol antioxidative therapy of parkinsonism. 1998. Ann Neurol. 44(3 Suppl 1):S160-S166.

58. Mahmood I. Clinical pharmacokinetics and pharmacodynamics of selegiline. An update. Clin Pharmacokinet. 1997;33(2):91-102.

59. Shin HS. Metabolism of selegiline in humans. Identification, excretion, and stereochemistry of urine metabolites. Drug Metab Dispos. 1997; 25(6):657-662.

60. Bar Am O, Amit T, Youdim MB. Contrasting neuroprotective and neurotoxic actions of respective metabolites of anti-Parkinson drugs rasagiline and selegiline. Neurosci Lett. 2004;355(3):169-172.

61. Binda C, Hubalek F, Li M, et al. Crystal structures of monoamine oxidase $\mathrm{B}$ in complex with four inhibitors of the N-propargylaminoindan class. J Med Chem. 2004;47(7):1767-1774.

62. Maruyama W, Naoi M. Neuroprotection by (-)-deprenyl and related compounds. Mech Ageing Dev. 1999;111(2-3):189-200.

63. Bar-Am O, Weinreb O, Amit T, Youdim MB. Regulation of Bcl-2 family proteins, neuroprotective factors, and APP processing in the neurorescue activity of propargylamine. FASEB J. 2005;19(13):1899-1901.

64. Murer MG, Yan Q, Raisman-Vozari R. Brain-derived neurotrophic factor in the control human brain and in Alzheimer's disease and Parkinson's disease. Prog Neurobiol. 2001;63(1):71-124.

65. Wang L, Muramatsu S, Lu Y, et al. Delayed delivery of AAV-GDNF prevents nigral neurodegeneration and promotes functional recovery in a rat model of Parkinson's disease. Gene Ther. 2002;9(6):381-389.

66. Mandel S, Weinreb O, Amit T, Youdim MB. Mechanism of neuroprotective action of the anti-Parkinson drug rasagiline and its derivatives. Brain Res Brain Res Rev. 2005;48(2):379-387.

67. Maruyama W, Akao Y, Carrillo MC, Kitani K, Youdim MB, Naoi M. Neuroprotection by propargylamines in Parkinson's disease: suppression of apoptosis and induction of prosurvival genes. Neurotoxicol Teratol. 2002;24(5):675-682.

68. Carrillo MC, Minami C, Kitani K, et al. Enhancing effect of rasagiline on superoxide dismutase and catalase activities in the dopaminergic system in the rat. Life Sci. 2000;67(5):577-585.

69. Akao Y, Maruyama W, Shimizu S, et al. Mitochondrial permeability transition mediates apoptosis induced by $\mathrm{N}$-methyl(R) salsolinol, an endogenous neurotoxin, and is inhibited by $\mathrm{Bcl}-2$ and rasagiline, N-propargyl-1(R)-aminoindan. J Neurochem. 2002;82(4):913-923.

70. Youdim MB, Amit T, Falach-Yogev M, Bar Am O, Maruyama W, Naoi M. The essentiality of Bcl-2, $\mathrm{PKC}$ and proteasome-ubiquitin complex activations in the neuroprotective-antiapoptotic action of the anti-Parkinson drug, rasagiline. Biochem Pharmacol. 2003;66(8):1635-1641.

71. Maruyama W, Akao Y, Youdim MB, Davis BA, Naoi M. Transfectionenforced Bcl-2 overexpression and an anti-Parkinson drug, rasagiline, prevent nuclear accumulation of glyceraldehyde-3-phosphate dehydrogenase induced by an endogenous dopaminergic neurotoxin, N-methyl(R)salsolinol. J Neurochem. 2001;78(4):727-735.

72. Weinreb O, Bar-Am O, Amit T, Chillag-Talmor O, Youdim MB. Neuroprotection via pro-survival protein kinase $\mathrm{C}$ isoforms associated with Bcl-2 family members. FASEB J. 2004;18(12):1471-1473.

73. Rabey JM, Sagi I, Huberman M, et al. Rasagiline mesylate, a new MAO-B inhibitor for the treatment of Parkinson's disease: a doubleblind study as adjunctive therapy to levodopa. Clin Neuropharmacol. 2000;23(6):324-330.

74. Stern MB, Marek KL, Friedman J, et al. Double-blind, randomized, controlled trial of rasagiline as monotherapy in early Parkinson's disease patients. Mov Disord. 2004;19(8):916-923. 
75. Freedman NM, Mishani E, Krausz Y, et al. In vivo measurement of brain monoamine oxidase B occupancy by rasagiline, using (11)C-1-deprenyl and PET. J Nucl Med. 2005;46(10):1618-1624.

76. Kupsch A, Sautter J, Gotz ME, et al. Monoamine oxidase-inhibition and MPTP-induced neurotoxicity in the non-human primate: comparison of rasagiline (TVP 1012) with selegiline. J Neural Transm. 2001;108(8-9):985-1009.

77. Heikkila RE, Duvoisin RC, Finberg JP, Youdim MB. Prevention of MPTP-induced neurotoxicity by AGN-1133 and AGN-1135, selective inhibitors of monoamine oxidase-B. Eur J Pharmacol. 1985;116(3):313-317.

78. Olanow CW, Rascol O, Hauser R, et al. A double-blind, delayedstart trial of rasagiline in Parkinson's disease. $N$ Engl J Med. 2009;361(13):1268-1278.

79. Hurley D. FDA committee: Rasagiline rejected as 'disease modifying' for Parkinson Disease. 2011;11(21):1, 6-7.

80. Parkinson Study Group. A controlled trial of rasagiline in early Parkinson disease: the TEMPO Study. Arch Neurol. 2002;59(12):1937-1943.

81. Parkinson Study Group. A controlled, randomized, delayedstart study of rasagiline in early Parkinson disease. Arch Neurol. 2004;61(4):561-566.

82. Fahn S, Oakes D, Shoulson I, et al. Levodopa and the progression of Parkinson's disease. N Engl J Med. 2004;351(24):2498-2508.

83. Hauser R, Lew M, Hurtig H, Ondo W, Wojcieszek J. Early treatment with rasagiline is more beneficial than delayed treatment start in the long-term management of Parkinson's disease: P251. Mov Disord. 2005;20:S75.

84. Parkinson Study Group. Effect of lazabemide on the progression of disability in early Parkinson's disease. Ann Neurol. 1996;40(1):99-107.

85. Shults CW, Oakes D, Kieburtz K, et al. Effects of coenzyme Q10 in early Parkinson disease: evidence of slowing of the functional decline. Arch Neurol. 2002;59(10):1541-1550.

86. Rascol O, Brooks DJ, Melamed E, et al. Rasagiline as an adjunct to levodopa in patients with Parkinson's disease and motor fluctuations (LARGO, Lasting effect in Adjunct therapy with Rasagiline Given Once daily, study): a randomized, double-blind, parallel-group trial. Lancet. 2005;365(9463):947-954.

87. Parkinson Study Group. A randomized placebo-controlled trial of rasagiline in levodopa-treated patients with Parkinson disease and motor fluctuations: the PRESTO study. Arch Neurol. 2005;62(2):241-248.
88. Montastruc JL, Chaumerliac C, Desboeuf K, et al. Adverse drug reactions to selegiline: a review of the French pharmacovigilance database. Clin Neuropharmacol. 2000;23(5):271-275.

89. Abassi ZA, Binah O, Youdim MB. Cardiovascular activity of rasagiline, a selective and potent inhibitor of mitochondrial monoamine oxidase B: comparison with selegiline. Br J Pharmacol. 2004;143(3):371-378.

90. Goetz CG, Schwid S, Eberly S, et al. Safety of rasagiline in elderly patients with Parkinson disease. Neurology. 2006;66:1427-1429.

91. Da Prada M, Zurcher G, Wuthrich I, Haefely WE. On tyramine, food, beverages and the reversible MAO inhibitor moclobemide. $J$ Neural Transm Suppl. 1988;26:31-56.

92. Parkinson Study Group. Tyramine challenge to assess the safety of rasagiline monotherapy in a placebo-controlled multicenter trial for early Parkinson's disease (the TEMPO Study). Neurology. 2001; 56 Suppl 3:A345.

93. Zornberg GL, Bodkin JA, Cohen BM. Severe adverse interaction between pethidine and selegiline. Lancet. 1991;337(8735):246.

94. Chen JJ, Ly AV. Rasagiline: A second-generation monoamine oxidase type-B inhibitor for the treatment of Parkinson's disease. Am J Health Syst Pharm. 2006;63(10):915-928.

95. Azilect.com [homepage on the Internet]. Anti-depressant chart review. Teva Neuroscience, Inc; 2010. Available from: http://www.azilect. com/HCP/Tools-Resources/Anti-Depressant-Fact-Card.aspx. Accessed February 13, 2012.

96. Chen JJ, Swope DM. Clinical pharmacology of rasagiline: a novel, second-generation propargylamine for the treatment of Parkinson disease. J Clin Pharmacol. 2005;45(8):878-894.

97. Azilect.com [homepage on the Internet]. Azilect dosage: Parkinson's disease medication dosing. Teva Neuroscience; 2010. Available from: http://www.azilect.com/HCP/Azilect-Therapy/Dosing.aspx. Accessed February 13, 2012.

98. Hanagasi HA, Gurvit H, Unsalan P, et al. The effects of rasagiline on cognitive deficits in Parkinson's disease patients without dementia: a randomized, double-blind, placebo-controlled, multicenter study. Mov Disord. 2011;26(10):1851-1858.

99. Hudry J, Rinne JO, Keranen T, Eckert L, Cochran JM. Cost-utility model of rasagiline in the treatment of advanced Parkinson's disease in Finland. Ann Pharmacother. 2006;40(4):651-657.
Neuropsychiatric Disease and Treatment

\section{Publish your work in this journal}

Neuropsychiatric Disease and Treatment is an international, peerreviewed journal of clinical therapeutics and pharmacology focusing on concise rapid reporting of clinical or pre-clinical studies on a range of neuropsychiatric and neurological disorders. This journal is indexed on PubMed Central, the 'PsycINFO' database and CAS.

\section{Dovepress}

The manuscript management system is completely online and includes a very quick and fair peer-review system, which is all easy to use. Visit http://www.dovepress.com/testimonials.php to read real quotes from published authors. 